\title{
Classe trabalhadora,
precarização e resistência
no Brasil da pandemia
}

Working class, precariousness, and resistance in pandemic-era Brazil

\begin{abstract}
Marco Aurélio Santana*
Resumo - O presente artigo analisa as relações entre trabalho e política no Brasil da pandemia. Isso é feito indicando os processos políticos e sociais que constituíram o mundo do trabalho atual no país, identificando as linhas mestras que o caracterizam, bem como apontando algumas formas de resistência que vêm sendo agenciadas pela classe trabalhadora e movimentos sociais para lhes fazer frente. Partimos da ideia de que o cenário de vida e trabalho no país mesmo antes da chegada da pandemia já tinha a marca da desproteção social, precarização, informalidade e desemprego. A emergência sanitária da Covid-19 deixa isso escancarado e torna mais graves os seus impactos. É por isso que as demandas apresentadas pela classe trabalhadora nesse contexto, ao mesmo tempo em que trazem a lume as agruras que passam em sua atividade laboral presente, lançam luz sobre os processos sociais e de trabalho que foram destituídos e constituídos no Brasil dos últimos anos, bem como apontam para futuros desdobramentos.

Palavras-chave: trabalho; classe trabalhadora; precarização; sindicatos; movimentos sociais.
\end{abstract}

\begin{abstract}
This article analyzes the relationship between labor and politics in Brazil during the COVID-19 pandemic. This is done by tracing the political and social processes that have built up today's world of labor in Brazil, identifying its main features, and also relating the ways the working class and social movements have struggled against it. Our main argument is that even before the pandemic the Brazilian world of labor was already marked by low social protection and high levels of precariousness, informality, and unemployment. The sanitary emergency brought by COVID-19 exposes this situation wide open and makes its impacts even more serious. That is why the demands presented by the working class in this context are relevant, as they bring to light the hardships in work activities, highlight the social and labor processes that were dismantled and implemented in Brazil in recent years, and point to future issues.

Keywords: labor; working class; precariousness; unions; social movements.
\end{abstract}

\footnotetext{
*Professor Titular de Sociologia do Departamento de Sociologia (DS) e do Programa de Pós-graduação em Sociologia e Antropologia da Universidade Federal do Rio de Janeiro (PPGSA-UFRJ). Possui graduação em Ciências Sociais pela Universidade Federal do Rio de Janeiro (1985), mestrado em Sociologia e Antropologia pela Universidade Federal do Rio de Janeiro (1992) e doutorado em Sociologia e Antropologia pela Universidade Federal do Rio de Janeiro (1998). Foi visiting PhD Student na University of Manchester (1995/1996), com bolsa da CAPES. Realizou Pós-doutorado na École des Hautes Études en Sciences Sociales (EHESS) (2005-2006), com bolsa do CNPq. E-mail: marcosilvasantana @gmail.com. ORCID: https://orcid.org/0000-0002-3181-6964.
} 


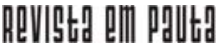

\} CLASSE TRABALHADORA, PRECARIZAÇÃO - SANTANA, M. A. \}

DOI: $10.12957 /$ REP.2021.60293

\section{Apresentação}

O presente artigo analisa as relações entre trabalho e política no Brasil da pandemia. Isso é feito indicando os processos políticos e sociais que nos levaram à constituição do mundo do trabalho atual no país, identificando as linhas mestras que o caracterizam, bem como apontando algumas formas de resistência que vêm sendo agenciadas pela classe trabaIhadora - entendida aqui na interseccionalidade de classe, raça, gênero e etnia - e pelos movimentos sociais para lhes fazer frente.

Partimos da ideia de que o cenário de vida e trabalho no país, mesmo antes da chegada da pandemia, já tinha a marca da desproteção social, precarização, informalidade e desemprego. A emergência sanitária da Covid-19 deixa isso escancarado e torna mais graves os seus impactos. É por isso que as demandas apresentadas pela classe trabalhadora nesse contexto, ao mesmo tempo em que trazem a lume as agruras por que passa esse grupo em sua atividade laboral presente, lançam luz sobre os processos sociais e de trabalho que foram destituídos e constituídos no Brasil dos últimos anos. Além disso, indicam um horizonte possivelmente ainda mais sombrio pela frente, bem como as formas de resistências a ele.

O artigo é dividido em quatro partes. Primeiro, é apresentada a construção do cenário social político, econômico e laboral encontrado pela pandemia quando de sua ocorrência no Brasil. Depois, especificamente, trata do quadro laboral já sob os impactos da pandemia. Na terceira parte estão em tela as duas mobilizações levadas a cabo pela categoria dos/as entregadores/as por aplicativo, ocorridas no mês de julho de 2020, e que simbolizaram a resistência da classe trabalhadora precária no contexto da pandemia. Por último, são avançadas algumas possibilidades indicadas no cenário em termos de organização e mobilização da classe trabalhadora, tentando-se escapar de visões mais excludentes sobre as possibilidades de articulação entre as formas históricas de organização e mobilização da classe trabalhadora e os seus desenhos experimentados na atualidade.

\section{Preâmbulos: a construção do cenário}

Acreditamos que, em termos sociais, políticos e econômicos, as condições materiais em que atua a classe trabalhadora brasileira hoje precisam ser entendidas em uma temporalidade um pouco mais longa do que apenas a do quadro pandêmico. Isso deve nos remeter ao início da década de 2010'. Apesar dos intensos desgastes com a crise do "mensalão" e as duras baixas que produziu no Partido dos Trabalhadores (PT), os índices de avaliação positiva do governo de Luiz Inácio Lula da Silva atingiram

'Para análises de todo esse período, sobre as questões tratadas nesse artigo, sob variados prismas, ver, entre outros, Druck (2005), Braga (2012), Singer (2014), Oliveira et al (2014), Ladosky e Rodrigues (2018) e Santana et al (2020). 
patamares extremamente altos. A elevada popularidade do presidente foi testada nas eleições de 2010, quando a sua ministra da Casa Civil, Dilma Rousseff, junto com Michel Temer, do Partido do Movimento Democrático Brasileiro (PMDB), como vice, representou a continuidade do governo, após o segundo turno, frente ao candidato de oposição José Serra, do Partido da Social Democracia Brasileira (PSDB).

A vitória de Dilma, de imagem pouco conhecida da maioria da população até então, foi, sem sombra de dúvida, uma vitória do governo e, principalmente, da popularidade de Lula. Dilma continuaria, no geral, os eixos de seus dois governos. Contudo, teria de enfrentar os impactos da crise capitalista internacional de 2008. Os ecos, dos quais Lula desdenhava se referindo às "marolinhas", demorariam a chegar, mas chegariam. O eixo condutor baseado na combinação de mercado interno, commodities e juros elevados dava ainda algum fruto, mas já mostrava seus sinais de esgotamento.

O primeiro governo Dilma teve de lidar com crescente onda de descontentamento da classe trabalhadora, explicitada nos números de greves, principalmente a partir de 2011, e nas rebeliões que assombraram o país em junho de 2013. Atravessado por várias contradições e fissuras, o projeto do PT no governo ia mostrando seu esgotamento.

Por outro lado, desde 2011 também, o governo Dilma foi assumindo uma política de baixar os juros, o que desagradou à fração financista, abrindo caminho para seu afastamento das bases de sustentação da política de conciliação estruturada por Lula, que brandia aos sete ventos, sempre que podia, que os bancos nunca tinham ganhado tanto dinheiro quanto em seu governo. Concomitantemente, dada a relação estabelecida por Dilma com partidos e políticos da base aliada, inclusive o próprio PT, seu trânsito no Parlamento foi dificultado.

Dilma levou este passivo, com vários destes problemas, para a eleição de 2014. E quase ficou pelo meio do caminho. A dura e acirrada disputa foi decidida por uma forte mobilização final de polarização contra o candidato do PSDB, Aécio Neves. Nesta polarização, contou o medo contra o retorno daquele partido ao poder e o retrocesso que poderia provocar nas políticas sociais. Mais um grande sinal havia sido dado e, liderada pelo PSDB, a oposição partiu para o ataque desde a primeira hora, pedindo recontagem dos votos.

Ao assumir seu segundo mandato, mesmo com a mobilização e a radicalização discursiva do último período da campanha, Dilma apresentaria um ministério de corte conservador, no qual figurava Joaquim Levy, diretamente vinculado aos setores do capital financeiro. Isso nem acalmou a banca, nem os setores progressistas e, por óbvio, trouxe apreensão a trabalhadores e trabalhadoras.

Dilma tentaria manter a toada econômica, somando-se aí o chamado ajuste fiscal, que impactava fortemente a classe trabalhadora. Além disso, a crise não dava tréguas. A oposição, sentindo-se fortalecida pelo 


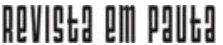

\} CLASSE TRABALHADORA, PRECARIZAÇÃO - SANTANA, M. A. \}

DOI: $10.12957 /$ REP.2021.60293

resultado eleitoral, continuou crivando o governo de críticas, produzindo o chamado "terceiro turno". Nestes termos, acusava a eleita de "estelionato eleitoral" por propor uma coisa na campanha e fazer outra logo no início do mandato.

O quadro tomaria contornos insustentáveis com o desenrolar da chamada Operação Lava Jato, disparada em 17 de março de 2014, que catapultou o juiz Sérgio Moro ao primeiro plano da vida pública nacional. A articulação entre setores do parlamento, do judiciário e da mídia mirou em Lula, no governo, no PT e em seu agora aliado próximo, o Partido do Movimento Democrático Brasileiro (PMDB). O governo se tornou, na prática, um morto ambulante, diante das dificuldades trazidas por este cenário. Pressões sincronizadas aumentavam a crise e jugulavam o governo. A mescla entre crise política e crise econômica, com desemprego de elevadas cifras - que atingiam patamares de $12 \%$, cerca de 12 milhões de trabalhadores -, produziu o caldo perfeito para o golpe parlamentar, judiciário e midiático, apresentado sob a forma de impeachment, que contou com forte apoio de movimentos organizados nas e pelas classes médias². No dia 31 de agosto de 2016, por 61 votos a 20, o Senado Federal aprovou a destituição da presidenta legitimamente eleita.

O golpe, que contou entre os seus urdidores com o empenho do vice Michel Temer, pôs fim, de forma abrupta e dramática, à experiência de mais de uma década de governos do PT. Um governo de aliança, orientado por uma política de conciliação de classes e marcado por muitas expectativas, atravessado por contradições, e que teve sensíveis resultados em diferentes áreas, mas também claros limites. Os impactos simbólicos e concretos da lógica política por trás do golpe, ainda que mirassem no PT, serviram também para impactar toda a esquerda e tudo o que ela representa.

Desde que assumiu a presidência, Temer, de imediato disse a que veio, pondo em marcha uma agenda de retomada do neoliberalismo puro em nosso país ${ }^{3}$. A cesta já é conhecida: ajuste fiscal, Lei da Terceirização ${ }^{4}$, reforma trabalhista, Proposta de Emenda Constitucional n. 241/ $2016^{5}$ e reforma da Previdência. O conjunto de mudanças nas regulações do trabalho, alterando radicalmente forma e conteúdos anteriores, troca o modelo legislado pelo modelo negociado, instituí o trabalho intermitente,

\footnotetext{
2 É importante notar que, para além do discurso de claro tom moralista contra a corrupção, que inflamava sobretudo as classes médias, ele mal mascarava uma linha subjacente marcada pelo preconceito de classe, pelo machismo, pelo anticomunismo etc.

${ }^{3}$ Deve-se indicar que esse processo de destituição da presidente é também, de certa forma, fruto e motor de uma maré regressiva na sociedade brasileira, na qual tem sido sensível o avanço de práticas excludentes, autoritárias, racistas, machistas, LGBTQfóbicas etc., em diversos espaços da vida social desde as redes sociais até o parlamento.

${ }^{4}$ Que ampliava a possibilidade de terceirização, até então franquiada apenas às atividades-meio, às atividade-fim. Isso significava garantir, na prática, que todos os setores e atividades poderiam lançar mão da terceirização, dando segurança jurídica a práticas que vinham sendo utilizadas de forma ilegal pelo empresariado.

${ }^{5}$ Apelidada pelos movimentos sociais de "PEC do fim do mundo", ela cria um teto para os gastos públicos, congelando as despesas do governo federal, com óbvios impactos nos gastos sociais, por 20 anos, com cifras corrigidas pela inflação.
} 


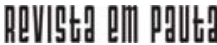

\} CLASSE TRABALHADORA, PRECARIZAÇÃO - SANTANA, M. A. \}

DOI: $10.12957 /$ REP.2021.60293

entre outras, no mesmo ato em que impõe sérias restrições financeiras aos sindicatos, aqueles que deveriam supostamente, no novo modelo, garantir alguma equidade nas negociações já tão desbalanceadas.

No desdobramento desse processo foi feito todo um forte e direcionado trabalho no sentido de manter Lula fora da eleição presidencial de 2018, inclusive com a sua prisão, que veio a ocorrer. Deve-se dizer que houve resistências importantes ao golpe (e ao cenário que ele acabara de implantar no país), e a classe trabalhadora participou delas, via, por exemplo, as chamadas frentes de mobilização, como a Povo Sem Medo e a Brasil Popular, bem como por outras formas de coalizão. Nesse sentido, além de manifestações importantes pelo Fora Temer, duas greves gerais foram deflagradas, sendo uma delas de sentido impacto pelo país.

O ano de 2018 foi marcado pelas eleições presidenciais, quando se realizou o fechamento do ciclo do golpe, agora através de uma legalidade e legitimidade eleitoral. Com Lula preso, o candidato com maior indicação de preferências nas pesquisas de opinião estava fora do jogo. Lula chegou a ter sua candidatura oficializada pelo PT, mas foi tornado inelegível pelo Tribunal Superior Eleitoral (TSE). Em uma corrida eleitoral mais curta do que as demais, várias candidaturas se colocaram. Duas polarizaram mais as expectativas: a de Fernando Haddad (aliança PT e Partido Comunista do Brasil [PCdoB]) e a de Jair Bolsonaro (do recém-criado Partido Social Liberal - PSL). Bolsonaro, representando setores defensores de uma pauta regressiva em termos morais e, agora, convertido ao liberalismo econômico, que já vinha impressionando desde os primórdios das pesquisas eleitorais, perdendo apenas para Lula, continuou crescendo em termos de força e, por pouco, não ganhou a eleição no primeiro turno. Fernando Haddad, que teve o lançamento de sua campanha retardado ao máximo em termos da legislação eleitoral, na expectativa de que Lula pudesse ainda vir a ser o candidato, passou ao segundo turno como opção alternativa a Bolsonaro.

A polarização entre as duas candidaturas remetia novamente não apenas ao processo eleitoral de 2014, mas, sobretudo, ao período das disputas travadas nas ruas e no parlamento durante o impeachment. Contra o que seria a volta do petismo, Bolsonaro aglutinou setores evangélicos, setores de classe média, base das manifestações pelo impeachment, setores ideologicamente reacionários e até mesmo os setores do grande capital que haviam apostado suas fichas em outros candidatos e que, agora, miravam para a única opção que restara contra o retorno do petismo. O convite negado por outros nomes antes - ao general Hamilton Mourão garantiu a simpatia militar, e ao economista neoliberal Paulo Guedes, conquistou a simpatia dos setores do capital. Bolsonaro, esquivando-se dos debates na $\mathrm{TV}$, ainda mais após o que teria sido um atentado contra ele, ganhou a disputa com uma pauta de liberalismo econômico e conservadorismo moral, e se pronunciou como, no que deveria já ser um surrado bordão, antissistema e representante da "nova política". 
A campanha foi pautada pelo forte uso das redes sociais, especificamente o aplicativo WhatsApp. Extensas e intensas campanhas que mobilizavam medos, pânicos e preconceitos sociais entupiram as redes sociais. Acusações sobre empresas que usavam robôs para a disseminação das chamadas fake news ganharam a imprensa e chegaram às barras dos tribunais eleitorais, mas nada que barrasse esse processo.

Deve-se notar também que alguns dos setores centrais na arquitetura e efetivação do impeachment saíram derrotados do pleito eleitoral. Partidos como o Democratas (DEM), o Movimento Democrático Brasileiro (MDB) - como passou a ser chamado o PMDB a partir de 2017 - e o PSDB, que esperavam obter dividendos eleitorais, viram suas forças serem drenadas fortemente, com desempenho risível no pleito, o que desbastou sua presença em termos de assentos no parlamento, ainda que o DEM tenha manejado para ocupar a presidência das duas casas. A esquerda, incorporando partidos como PT, Partido Socialismo e Liberdade (PSOL), Partido Democrático Trabalhista (PDT) e PCdoB, não teve perda considerável de assentos no legislativo. Já os setores vitoriosos na eleição levantaram do chão um partido que, pouco antes, tinha representação mínima, o PSL, o qual passou a ser a segunda bancada da noite para o dia, perdendo apenas para o PT, e do qual Bolsonaro rapidamente se distanciaria, por conta de tensões internas, mas que continuaria com fiéis membros de sua base parlamentar.

Com a eleição de Bolsonaro, uma nova etapa do golpe se cumpriu, assumindo legitimidade eleitoral. Na pauta central do governo, figurava a reforma da Previdência, que já estava na agenda do golpe, mas que Temer não conseguira efetivar, dados os imbróglios das denúncias que o cercaram. Para além da névoa da chamada pauta moral, a pauta regressiva neoliberal teria no governo Bolsonaro um fiel escudeiro, que, inclusive, extingue o ministério do Trabalho em uma clara demonstração de sua visão sobre o tema. Reforma da Previdência, privatizações, ataques ao serviço público e ao tamanho do Estado etc. estarão na ordem do dia, umas mais no discurso do que na prática. Para a classe trabalhadora, como estava claro como motivos para o golpe, o cenário da regulação e proteção do trabalho que se abrira então, com a Lei da Terceirização e a reforma trabalhista, se associava ao desemprego em números explosivos, à paralisia econômica, ao crescimento da informalidade etc.

Junte-se a isso a grande ofensiva do omnipresente discurso do empreendedorismo, transformado em salvação, que coloca a responsabilidade de superação da crise sobre os ombros das/os trabalhadoras/es além de anular a própria identidade delas/es, pois não se reconhecem mais como tal -, e as transformações trazidas pela acelerada introdução de tipos de trabalho por aplicativos, assim como as possibilidades por eles abertas. Frente a tudo isso, a classe trabalhadora brasileira vai viver uma das etapas mais difíceis de sua história em termos tanto de condições de vida e trabalho, quanto de organização e mobilização contra situação tão adversa. 


\section{A pandemia}

Se não bastasse todo o quadro descrito acima, em 2020 o país, como o resto do mundo, foi colocado de pernas para o ar com a chegada da pandemia da Covid-19. Ela revelaria e agravaria o verdadeiro resultado desse conjunto de reformas sobre a classe trabalhadora e os setores mais vulneráveis de nossa sociedade. Isso ficou material, simbólica e tragicamente claro no fato de que a primeira vítima no Brasil foi uma trabalhadora doméstica, contaminada no espaço de trabalho pela patroa que voltara de um tour pela Europa. Os locais de trabalho e o deslocamento até eles nas aglomerações no péssimo sistema de transportes coletivos se tornaram pontos de contágio importantes. A visão ilusória de que na pandemia "estamos todos no mesmo barco" e de que ela é "democrática" em seus impactos, foi desmascarada rapidamente quando todos os números passaram a mostrar que a sua tragédia, por óbvio, tem classe, raça, gênero e etnia. São os já vulnerabilizados socialmente os mais atingidos. ${ }^{6}$

O governo Bolsonaro deixou claro desde o início que trataria o gravíssimo quadro pandêmico com negacionismo, o que orienta todas as medidas federais sobre a questão. Seus discursos e práticas, criando dúvidas e duplicidades de entendimento na população, prejudicaram bastante o enfrentamento da doença no país, o que é demonstrado pelo trágico número de mortes.

As políticas do governo diante da pandemia, direta ou indiretamente, visavam proteger o empresariado e as empresas. Porém, mesmo nesse caso, por problemas de desenho e execução, deixaram parte desse setor em dificuldades, principalmente as empresas de pequeno porte, que são aquelas que empregam muita gente. O programa de proteção ao emprego e à renda, mesmo dizendo que era para proteção dos trabalhadores, os obrigou a, na prática, ter de aceitar as medidas de suspensão e redução de jornada e salário, em parte apenas recomposta por benefício criado pelo governo. Lembremos que, em sua primeira versão - embora depois fosse modificada, dada a grita causada -, não estava previsto qualquer auxílio protetivo para trabalhadores/as que tivessem seus contratos de trabalho suspensos; eles/as simplesmente ficariam à míngua.

Essas medidas, como era sabido - e o governo nada fez para atenuar isso -, teriam impactos também nos rendimentos futuros da classe trabalhadora, como no caso do $13^{\circ}$ salário. Além de ter colocado a questão

\footnotetext{
${ }^{6}$ Segundo estudo publicado no Jornal Britânico de Medicina, para o período de março a agosto de 2020, em São Paulo, com dados de contaminações, internações e mortes em decorrência de Covid-19, comparando índices por regiões ricas e pobres, por condições socioeconômicas e raciais temos que as desigualdades sociais e raciais têm clara influência sobre os números relacionados à pandemia. O estudo indica que "Social and racial inequalities shape the risk of SARI hospitalisation and death. (...) Black or Pardo Brazilians and individuals residing in low-income areas were more likely to be hospitalised and die with SARI compared with White individuals and those from wealthier areas" (Li, Pereira, Prete Jr. et al, 2021, p. 8). Comparando-se, por exemplo, negros e brancos, o risco relativo de morte para os primeiros é cerca de $80 \%$ maior.
} 


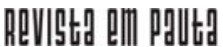

\} CLASSE TRABALHADORA, PRECARIZAÇÃO - SANTANA, M. A. \}

DOI: $10.12957 /$ REP.2021.60293

em termos do "é isso ou o desemprego", quando sabemos que havia muitas outras possibilidades que levassem em conta a proteção de trabalhadores e trabalhadoras, nada foi feito para atenuar perdas futuras. Aqui se tem um ponto: eram essas as únicas medidas que se poderia tomar para proteger emprego e renda no setor formal? Por suposto, não.

No contexto das políticas regressivas que vêm sendo impostas no país após o golpe de 2016, não é de hoje que as condições de vida e trabalho da classe trabalhadora passam longe das preocupações de governos e legisladores. Muito pelo contrário. Em um mercado de trabalho marcado pela informalidade, precarização e desemprego, a pandemia deu o toque final e serviu de espaço para que muitas medidas estejam sendo impostas. Essas, mesmo trazendo termos como "proteção de emprego e renda", têm muito pouco a ver com esse tipo de ideia, sendo muito mais medidas voltadas, ainda que problematicamente, para a proteção dos setores do capital. O governo vislumbra cerca de 24,5 milhões de contratos assinados, já tendo atingido, em dezembro de 2020, final do período, cerca de 20 milhões. Em abril de 2021, o governo relançaria o Programa.

No sentido mais amplo de tentativa de lidar com a devastação dos impactos da pandemia, o governo se viu obrigado a conceder um Auxílio Emergencial, que planejou ser de baixíssimo valor, mas que, dadas as pressões no parlamento, teve de aumentar ${ }^{7}$. Poderiam acessar esse auxílio qualquer cidadão/ã que estivesse na condição de desempregado/a ou exercendo atividade como: microempreendedores/as individuais (MEI), contribuinte individual da Previdência Social e trabalhador/a informal, que pertencesse à família cuja renda mensal por pessoa não ultrapassasse meio salário mínimo ( $R \$ 522,50)$, ou, ainda, cuja renda familiar total fosse de até três salários mínimos $(\mathrm{R} \$ 3.135,00)^{8}$.

O quadro de distribuição desses recursos foi caótico, obrigando os mais desfavorecidos a penarem nas filas da Caixa Econômica Federal (CEF). Segundo dados oficiais para agosto de 2020, cerca de 65 milhões de pessoas teriam recebido esse auxílio, que atingiu no referido mês cerca de $45 \%$ dos lares do país. Tendo em vista o cenário estrutural brasileiro e seu agravamento conjuntural, o Auxílio Emergencial teve impactos em termos da desigualdade durante a pandemia. Tanto que o governo viu nisso uma possibilidade de torná-lo um programa fixo com claro intento eleitoral, dada a óbvia relação entre o auxílio e os índices de aprovação do governo em certos setores sociais. Segundo avaliação de Laura Carvalho,

o auxílio emergencial foi capaz de evitar uma perda de renda para a me-tade mais pobre da população brasileira durante essa que é a mais profunda recessão de que temos notícia. Então, houve, sim, uma perda de renda maior para os mais pobres quando a gente pensa

\footnotetext{
${ }^{7}$ O governo propunha $\mathrm{R} \$ 200,00$ e teve de aumentar para $\mathrm{R} \$ 600,00$.

${ }^{8}$ Disponível em: https://www.caixa.gov.br/auxilio/Paginas/default2.aspx. Acesso em: 3 nov. 2020.
} 
em renda do trabalho, mas, quando a gente soma o auxílio emergencial, o índice de Gini, que mede a desigualdade, até cai durante a pandemia por conta desse programa. Ou seja, o auxílio foi capaz de neutralizar completamente o aumento da desigualdade que houve no mercado de trabalho durante a pandemia ${ }^{9}$.

Se observarmos diretamente o quadro de trabalho e não trabalho da forma em que se estabeleceu durante a pandemia, segundo os dados do Instituto Brasileiro de Geografia e Estatística (IBGE) na Pesquisa Nacional por Amostra de Domicílios (Pnad) Covid-1910 em 2020 atingimos a casa dos 13,5 milhões de desempregados em nosso país, com tendência de aumento, dadas as políticas de flexibilização do isolamento social, permitindo que mais pessoas estivessem à procura de emprego ${ }^{11}$. $\mathrm{O}$ fechamento de postos de trabalho se deu, ainda que em níveis diferentes, nos mais variados setores econômicos. De março a setembro de 2020, segundo Mazza, Amorozo e Buono (2020, n.p.),

o país fechou 897 mil vagas de trabalho. O setor de serviços e o comércio foram os mais afetados pela crise. Ao todo, foram extintas 181 mil vagas de vendedores em lojas e mercados - o dobro do número de vagas fechadas na indústria, em geral. Na Educação, 36 mil vagas de professor foram fechadas. Trabalhadores domésticos, um dos primeiros a terem o trabalho afetado pela pandemia, sofreram um baque: entre março e setembro, 1,4 milhão de brasileiros que exerciam essa profissão perderam o emprego.

Os impactos gerais desse processo, que, como vimos, foram de monta, tiveram seus rebatimentos desiguais por setores e categorias, e também em termos das clivagens e composições de seus grupos sociais. Os jovens (15-29 anos), por exemplo, foram duramente atingidos. Segundo Corseuil e Franca (2021, p. 96)

A proporção de jovens ocupados, que era de 48,6\%, no primeiro trimestre de 2020 , atingiu $41,4 \%$ já no trimestre seguinte, o que significa uma queda de 7,2 p.p. em apenas um trimestre. Essa queda na ocupação foi mais acentuada do que a redução de 5,8 p.p. registrados entre os primeiros trimestres de 2015 a 2017.

\footnotetext{
${ }_{9}^{9}$ Disponível em: https://apublica.org/2020/11/laura-carvalho-auxilio-emergencial-foi-ajuda-significativa-mas-deixaradesigualdade-como-heranca/. Acesso em: 3 nov. 2020.

${ }^{10}$ Disponível em: https://covid19.ibge.gov.br/pnad-covid/.

${ }^{11}$ Os números do desemprego seriam ainda piores no primeiro trimestre de 2021, como apontado nas tendências anteriores, atingindo, segundo números do IBGE, a marca de 14,8 milhões de pessoas $(14,7 \%)$, maior $6,3 \%$ que o trimestre anterior, um novo recorde histórico para a série iniciada em 2012. O número de desalentados é de 5,9 milhões. A taxa de desemprego entre as mulheres bateu recorde também alcançando cerca de $18 \%$. Disponível em https://agencia denoticias.ibge.gov.br/agencia-sala-de-imprensa/2013-agencia-de-noticias/releases/30792-pnad-continua-taxade-desocupacao-e-de-14-7-e-taxa-de-subutilizacao-e-de-29-7-no-trimestre-encerrado-em-marco . Acesso em: 27 mai. 2021.
} 
Nesse grupo, os impactos também produziram efeitos desiguais especificados em termos de gênero. Segundo Corseuil e Franca (2021, p. 97), comparando o segundo trimestre de 2020 com o de 2019, mais de cinquenta por cento das mulheres jovens estavam fora da força de trabalho, significando um aumento de 9,2\%. No caso dos homens, com 38\% de inativos, esse aumento foi de $8,5 \%$.

A pandemia atuou ainda fortemente sobre os números de jovens que não estudam e nem trabalham. Esse já era um índice importante antes da crise sanitária, contudo, com suas especificidades, ela pressionou ainda mais contribuindo para "aumentar o contingente de jovens que inter-rompem seus estudos e param de buscar emprego, ampliando o grupo dos jovens nem-nem desengajados da força de trabalho" (SILVA E VAZ, 2021, p. 105), o que terá certamente sérios desdobramentos futuros. Segundo Neri (2021, p. 18) "com a chegada da pandemia depois de 2019.4 (leia-se último trimestre de 2019) a taxa de jovens nem-nem que se encontrava em $23,66 \%$ acelera, chegando ao recorde histórico de $29,33 \%$ no segundo trimestre do ano, depois refluindo para $25,52 \%$ até $2020.4 "$, com maiores percentuais, entre outros, para mulheres $(31,29 \%)$, negros $(29,09 \%)$, Nordeste $(32 \%)$ e moradores de periferia das maiores metrópoles brasileiras $(27,41 \%)$.

Todo esse cenário laboral dramático, em meio à desproteção social e sanitária, assume tons ainda mais graves quando observamos os dados de desligamentos por mortes de trabalhadores e trabalhadoras. Quando se compara o primeiro trimestre de 2020 e o primeiro trimestre de 2021, no setor celetista, por exemplo, temos que entre

todas as atividades econômicas, as que apresentaram maior crescimento no número de desligamentos por morte estão: educação, com $106,7 \%$, transporte, armazenagem e correio, com 95,2\%, atividades administrativas e serviços complementares, com 78,7\% e, saúde humana e serviços sociais (agregado), com 71,7\% (DIEESE, 2021 a, p.4).

Esse quadro ${ }^{12}$ vai encontrar as entidades sindicais ainda bastante impactadas pelas mudanças da regulação trabalhista efetivada na conjuntura anterior, principalmente em termos de sustentação financeira. Com a pandemia, novas complexidades organizativas e mobilizatórias se apresentaram, aumentando os desafios postos aos sindicatos e suas lideranças, já que, como indica Campos (2020, p. 3),

as recomendações sanitárias impuseram limitações ao funcionamento das entidades sindicais e ao trabalho de base de suas lideranças relacionadas tanto às restrições à circulação de pessoas quanto ao fechamento de locais de trabalho, desafiando sua capacidade de diálogo e representação.

\footnotetext{
${ }^{12}$ Para um conjunto de análises sobre o universo do trabalho brasileiro na pandemia, ver, entre outros, Oliveira e Pochmann (2020)
} 


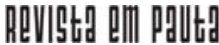

\} CLASSE TRABALHADORA, PRECARIZAÇÃO - SANTANA, M. A. \}

DOI: $10.12957 /$ REP.2021.60293

A classe trabalhadora brasileira - que se vê sob um governo que despreza a doença e as proteções sociais -, salvo o setor público, que con-seguiu garantir seus direitos apesar das pressões, se dividiu em grupos, entre outros, que estão no desemprego em massa, com contratos suspensos ou de redução de jornada e salário, e na informalidade.

Em termos de estratégias, onde foi possível, às empresas, além da supensão de contratos e redução de jornadas e salários, acelerarem a implantação do chamado home office, que cobriu cerca de 15\% de nossa força de trabalho. Ao mesmo tempo em que protege setores da classe trabaIhadora da exposição, essa forma de trabalho, com já claros impactos na saúde física e mental, separa os coletivos de trabalho, isola individualmente trabalhadores/as, dificulta a agência coletiva e sindical, obriga os/as trabaIhadores/as a cargas horárias extensas e pesadas, transformando o espaço da casa em local de trabalho. Essa forma de trabalho tem impactado sobretudo as mulheres, dadas as múltiplas jornadas já impostas no espaço dos lares. Muitas dessas mudanças, mesmo com a flexibilização das medidas sanitárias restritivas, parecem continuar indicando que as empresas usaram as práticas emergenciais no contexto de pandemia também como experiência para tempos futuros.

\section{Resistências: os/as precários/as vão à luta}

O advento da pandemia foi, por óbvio, um duro baque na sociedade brasileira. Porém, como era de se esperar, ela não se abateu sobre o conjunto social da mesma forma, mas, ao contrário, impacta sempre mais os/as já vulnerabilizados/as. O necessário isolamento social, que direta ou indiretamente obrigou a uma retirada das ruas, da circulação e do encontro, e as interações por telas tiveram claros impactos nas sociabilidades em geral, sobretudo naquelas que têm no encontro coletivo nas ruas um de seus centros de existência. A esquerda brasileira, que já vinha sofrendo com os reflexos do golpe de 2016, com as mudanças sociais e laborais que ele possibilitou e com a derrota social e eleitoral de 2018, na pandemia, além do encrustamento institucional já sentido, perdeu ainda mais esse pé da rua, tentando, ainda que de forma um tanto sofrível, se utilizar mais intensamente das redes sociais.

Isso fez com que, em um primeiro momento, apenas setores identificados com o governo continuassem a se utilizar da rua, ocupando-a com suas manifestações, sendo criticados socialmente pela produção de aglomeração e possibilidade de espalhamento do vírus. Somente quando esse grupo recrudesceu seu discurso e ação antidemocráticos, apoiado pelo governo, foi que setores da esquerda e dos movimentos sociais, e até setores de torcidas organizadas de futebol, saíram às ruas em atos públicos antifascistas e pela democracia, para tentar fazer frente a esse avanço. Nesse 


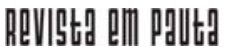

\} CLASSE TRABALHADORA, PRECARIZAÇÃO - SANTANA, M. A. \}

DOI: $10.12957 /$ REP.2021.60293

sentido, foram eficazes, junto com as lentas reações das instituições democráticas. Importante também, nesse conjunto, os atos antirracistas que ocorreram em diversas capitais.

Como já indicamos, o movimento sindical ainda nem tinha se recuperado dos impactos da conjuntura anterior e já teria de lidar com um cenário que dificultava ainda mais suas possíveis ações. Eles tiveram trabalho importante, onde foi possível, por exemplo, no sentido da negociação dos processos de suspensão parcial ou integral dos contratos de trabalho, garantindo, sempre que a correlação de forças permitiu, que o rolo compressor e a devastação não fossem totais. Podemos imaginar o que ocorreu em setores sem ou de baixa representação sindical.

De todo modo, apesar das grandes limitações da emergência sanitária, o mundo do trabalho brasileiro se movimentou em termos de mobilizações e greves, com variação de tipo, demanda, setor, duração e resultado. Segundo levantamento do Departamento Intersindical de Estatística e Estudos Socioeconômicos (DIEESE), o ano de 2020 se encerrou

registrando 649 greves. Pouco mais de dois terços (64\%) organizadas por trabalhadores da esfera privada; pouco menos de um terço (30\%) por trabalhadores da esfera pública (funcionalismo público e empresas estatais). O total anual representa uma queda de $42 \%$ em relação às 1.118 greves deflagradas em 2019 (DIEESE, 2021 b, p. 27).

Estas greves portaram um conjunto variado de demandas que tiveram, cada um a sua maneira e medida, a marca dos impactos da pandemia nos diversos setores da classe trabalhadora, com pautas que vão desde questões salariais até as da proteção contra os riscos de contágio. Ao observarse o quadro do reivindicado pelas mobilizações temos que as relacionadas

ao pagamento de vencimentos em atraso (salário, férias e 13\%) foram as mais frequentes $(40 \%)$. Em seguida, presente em $22 \%$ das greves, está a exigência de reajuste nos salários e nos pisos salariais - e também, com a mesma participação percentual, as questões relacionadas à alimentação. Itens relacionados às condições de segurança e ao fornecimento Equipamentos de Proteção Individual (EPIs) ocuparam $16 \%$ da pauta grevista, em 2020. Destaques para reivindicações relacionadas à pandemia de Covid-19 (DIEESE, 2021, p. 6).

Contudo, nada foi tão marcante nesse contexto de pandemia quanto a mobilização dos setores precários da classe trabalhadora. Nesse sentido, o mês de julho de 2020 já entrou para a longa lista de momentos luminosos da luta da classe trabalhadora brasileira ${ }^{13}$. A greve de entregadores

\footnotetext{
${ }^{13}$ A categoria já vinha atraindo atenção de análises acadêmicas, mas não há como negar que, com sua mobilização, atraiu ainda mais o investimento analítico. Sobre a mobilização, ver: Santana e Braga (2020), Abilio (2020), Galvão (2020a; 2020b), Praun (2020), Dutra e Festi (2020). Sobre as condições de trabalho da categoria na pandemia, ver: Abilio et al. (2020). Para a questão da regulação trabalhista, ver, entre outros, Antunes e Filgueiras (2020).
} 


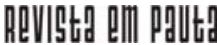

\} CLASSE TRABALHADORA, PRECARIZAÇÃO - SANTANA, M. A. \}

DOI: $10.12957 /$ REP.2021.60293

e entregadoras, ou o \#brequedosapps, ocorrida em dois atos nos dias $1^{\circ} \mathrm{e}$ 25, agitaram a cena pública com sua mobilização que tomou conta de várias capitais do país. Eles/as se situaram na ponta mais aguda da luta contra a precarização do trabalho e da vida no país, em um quadro de desproteção social instituído.

Como já apontado, o cenário antes da chegada da pandemia já tinha marcas ruins, e a emergência sanitária tornou isso ainda pior. É por isso que demandas apresentadas por entregadores e entregadoras - em sua maioria jovens, homens e negros, mas que incorpora um contingente crescente de mulheres ${ }^{14}$ - indicavam para muito além dos problemas experimentados em sua atividade de trabalho; desvelavam os processos sociais e de trabalho que nos haviam trazido até ali, e apontavam tanto para o possível espalhamento daquele quadro para amplos setores da classe trabalhadora, como para as possíveis resistências a ele.

A categoria já se fazia presente circulando apressada e anonimamente por nossas cidades, sendo detectável visualmente pelas motos, bikes ou a pé, pelas mochilas de cores fortes e com nomes de empresas de aplicativos de entrega nas costas, garantindo com seu próprio risco a manutenção do isolamento de diversos setores sociais. Contudo, ela marcou o espaço público de forma diferente naquele mês, e o fez como sujeito coletivo que demanda aumento da remuneração e melhores condições de trabalho. Ao fazer isso em direção às empresas, o movimento teve impactos em um universo muito mais amplo de espaços e atores sociais, políticos e econômicos, repercutindo nas empresas, na opinião pública e em consumidores/ as, nos partidos políticos, no meio sindical, no legislativo, no judiciário etc. Coletivamente, saíram da invisibilidade social, individualizada e anônima, para a visibilidade social e política ${ }^{15}$. Era um movimento por reconhecimento e redistribuição (FRASER; HONNETH, 2003).

A pauta apresentada publicamente pelo movimento de entregadores e entregadoras traz pontos como o aumento do valor mínimo da entrega, aumento do valor por $\mathrm{km}$ percorrido, seguro de roubo, acidente e vida, fornecimento de equipamentos de proteção individual (EPI), como álcool em gel e máscaras, auxílio-doença em caso de afastamento por contaminação pela Covid-19 e o fim dos bloqueios e desligamentos indevidos.

\footnotetext{
${ }^{14}$ Para dados de perfil e condições de trabalho da categoria antes da pandemia, ver, entre outros, https://www.ilocomo tiva.com.br/single-post/2019/04/29/estad\%C3\%A3o-na-crise-aplicativos-como-uber-e-ifood-viram-maiorempregador-do-pa\%C3\%Ads. e https://inforex.com.br/editorias/transportes/economia-compartilhada-gera-rendapara-milhoes-de-familias-conheca-o-raio-x-dos-entregadores/. Para dados de perfil da categoria e condições de trabalho durante a pandemia, ver Abílio et al. (2020), https://www.uol.com.br/tilt/noticias/redacao/2020/05/07/pesquisaentregadores.htm. e https://www.cnnbrasil.com.br/business/2021/04/12/cerca-de-11-4-milhoes-de-brasileiros-de pendem-de-aplicativos-para-ter-uma-renda.

${ }^{15} \mathrm{~A}$ ideia dessa passagem, via organização e mobilização, da invisibilidade social/individual para a visibilidade política/coletiva tem nos orientado desde a análise feita no dia seguinte ao primeiro "breque dos apps". Disponível em: https://www.brasildefato.com.br/2020/07/02/quem-apostou-no-fracasso-da-greve-dos-entregadores-perdeuafirma-sociologo). Ela será retomada no dia do segundo "breque" em Santana e Braga (2020).
} 


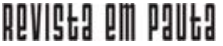

\} CLASSE TRABALHADORA, PRECARIZAÇÃO - SANTANA, M. A. \}

DOI: $10.12957 /$ REP.2021.60293

Dadas as clivagens que atravessam a categoria, vários outros pontos surgiram aqui e ali, mas esse primeiro conjunto é aquele que acabou sendo o mais convergente em termos de demandas unitárias possíveis. Esse processo de construção de identidades, bastante disputado em sua formação, não foi algo fácil, tendo sido marcado por uma complexa dinâmica social e política. Dele fizeram parte, entre outros, trabalhadores e trabalhadoras, diversas entidades que representam ou buscam representar a categoria ou parte de seu contingente, páginas e grupos organizados nas redes sociais, agrupamentos políticos etc., sem falar da própria tentativa de interveniência das empresas nesse processo.

As falas demonstram certo consenso sobre o grau de exploração ao qual esses/as trabalhadores/as estão submetidos/as pelas empresas e acerca do papel central de sua mobilização direta na tentativa de alteração desse quadro, buscando o que seriam resultados "urgentes", já que não se poderia "esperar mais". Apesar disso, havia um amplo espectro de ideias e práticas no seio da categoria e entre os que estiveram à frente da organização e mobilização. la, por exemplo, desde os/as que defendiam a Consolidação das Leis do Trabalho (CLT), os que queriam uma regulação específica, até os/as que não queriam qualquer tipo de regulação; havia também os/as que se diziam sem querer envolvimento político e mesmo os que esposavam as lutas políticas mais gerais; além desses, os/as que diziam querer afastamento de formas sindicais tradicionais, bem como os que a elas estavam já filiados etc.

É preciso lembrar que esses trabalhadores e trabalhadoras enfrentaram uma luta para lá de desigual. Enfrentaram a velha relação de exploração capitalista, agora em sua versão algorítmica. As empresas, entre as maiores empregadoras do país, se recusam a aceitar qualquer vínculo enquanto tal com seus/as trabalhadores/as. Se escondem atrás do argumento - insustentável - de que, nesse caso, são meras ferramentas de intermediação entre restaurantes, entregadores/as e consumidores. Entregadores e entregadoras, nessa visão maquiada da realidade, não são seus/as trabaIhadores/as, são "prestadores de serviço" e "parceiros".

A realidade, para além da "nuvem", não deixa dúvida sobre o que se passa. A sofisticação hype digital produz formas intensas - e nada hypes - de precarização do trabalho e da vida. É uma economia do compartilhamento em que as empresas pouco compartilham seus enormes ganhos com trabalhadores e trabalhadoras. Nessa gig economy, a classe trabalhadora faz "bicos" de 8, 10, doze horas por dia em troca de baixa remuneração e condições de trabalho precárias. As empresas têm se preocupado mais com publicidade, imagem, acionistas e investidores do que com os trabalhadores/ as dos/as quais retiram sua riqueza.

O movimento, sem qualquer sombra de dúvidas, foi um sucesso em termos políticos e organizativos. Nem todo mundo acreditava que a classe pudesse efetivar um movimento nacional de monta. Sobretudo sendo 


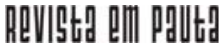

\} CLASSE TRABALHADORA, PRECARIZAÇÃO - SANTANA, M. A. \}

DOI: $10.12957 /$ REP.2021.60293

submetida a tal grau de informalidade e precarização, sob o controle e a pressão de sofisticados mecanismos tecnológicos, mas também de relações de trabalho autoritárias já bem conhecidas por nós, sendo obrigada a intensos e extensos ritmos e jornadas de trabalho, no "corre", sem poder parar. Mas conseguiu. Lançando mão de um rico ativismo digital e forte mobilização concreta, o movimento foi expressivo em várias capitais importantes, impactou o oferecimento de serviço, conseguiu redução de pedidos em alguns momentos, indicando relativa solidariedade social ativa dos usuários, logrou a publicização de suas condições precárias de trabalho, bem como expôs negativamente as marcas das empresas nelas envolvidas.

No entanto, para além disso, ganhos importantes foram sendo conseguidos no bojo da organização e no desenrolar do movimento: a constituição de um sujeito coletivo com demandas que se organizam e são postas na cena pública; a preparação da mobilização via articulação nacional, que demandou intenso fluxo de comunicação eletrônica; bem como, em uma categoria bastante diversificada nesse sentido, a importante politização à esquerda de setores do movimento, como os "entregadores antifascistas". A manifestação, sobretudo, colocou explicitamente a centralidade do trabalho e das lutas oriundas desse universo.

Pensar as repercussões desse movimento impõe mirar em diferentes níveis e dimensões. Como sabemos, "movimentos movimentam" e, creio, o mundo social, político e laboral se movimentou tendo em vista o movimento de $1^{\circ}$ de julho. A máquina institucional legislativa se movimentou nos níveis estaduais das assembleias legislativas, por exemplo do Rio e de São Paulo, na tentativa de dar conta das demandas sobre algum tipo de regulação do trabalho presentes em setores do movimento, e, em níveis federais, com a reunião entre o presidente da câmara dos deputados e representantes de contingentes da categoria - lembrando que já existem cerca de 20 projetos tramitando no Parlamento brasileiro. Essas movimentações não significaram alterações imediatas, pois aí também sofrerão a pressão das empresas no sentido de reduzir ao máximo as possibilidades de regulação de suas formas de gestão e uso do trabalho, que é central para elas nas suas estratégias de negócios.

O mesmo ocorre em termos das máquinas de representação da categoria, que é atravessada por organizações autônomas, sindicatos, associações etc. Esses grupos concorrem pela representação de trabalhadores e trabalhadoras e vêm demonstrando maior presença e atividade desde o anúncio do movimento. Agora, é preciso acompanhar para ver, entre outros, os desdobramentos das possibilidades de aproximação ou não das organizações de corte mais horizontal com aquelas mais verticais, ou das com estrutura de movimento social com aquelas mais institucionalizadas.

As empresas, que também apostaram no fracasso do movimento e trabalharam por isso, sentiram o impacto e têm buscado, via notas públicas e campanhas de publicidade, produzir versão alternativa sobre as condições 


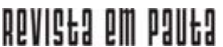

\} CLASSE TRABALHADORA, PRECARIZAÇÃO - SANTANA, M. A. \}

DOI: $10.12957 /$ REP.2021.60293

de trabalho da categoria no debate público. Mesmo que isso também não queira dizer que aceitarão as demandas colocadas, elas foram forçadas a sentar para negociar, saindo de sua postura olímpica de que nada estava acontecendo e de que seus/as "parceiros/as" viviam no melhor dos mundos.

Houve grande repercussão na opinião pública, que tomou conhecimento das condições de trabalho daqueles e daquelas que são identificados/as visualmente - mas são invisíveis socialmente - em nossas paisagens urbanas e nas portas de casas e prédios em todas as cidades, com suas mochilas coloridas com nomes de empresas às costas, até então anônimos. Isso graças, em grande medida, ao intenso ativismo digital da categoria nas redes sociais. O relativo engajamento por parte dos usuários na diminuição do volume de pedidos no dia da paralisação pode ajudar como possível indicador.

Os ganhos políticos e organizativos e as repercussões do \#breque dosapps são bastante sensíveis. Seu movimento fez mover. Ainda não está dado, uma vez que permanece em disputa, o caminho que será trilhado pela categoria após essas duas mobilizações. Em grande medida, ele dependerá de suas escolhas trabalhistas, políticas e organizativas. De todo modo, esse movimento se rebelou contra processos que atingem muitos outros setores, incorporando grandes contingentes de trabalhadores e trabalhadoras, e que tenderá a se espalhar ainda mais. Resta claro que o plano do capital é caminhar a passos largos para a informalidade e a precarização de todo o mundo do trabalho. Isso só foi barrado ao longo da história pela organização e mobilização da classe trabalhadora. Esse passo teve em nosso país, em julho de 2020, um marco importante.

Assim, a luta de entregadores e entregadoras contra a precarização do trabalho e da vida forneceu grande contribuição para abrir e orientar caminhos para muitos outros setores e movimentos nessa direção. Não se poderá falar da pandemia e de seus impactos laborais no Brasil sem falar da resistência da classe trabalhadora, principalmente dos/as trabalhadores/ as precários/as.

\section{Possíveis formas e dinâmicas futuras}

Ao longo de toda a pandemia, que ainda grassa, ficou famosa a ideia do chamado "novo normal", o qual passaria a ser o orientador de nossa existência social após a passagem da emergência sanitária. A ideia é pouco clara e está muito ligada aos interesses do enunciador, quase sempre passando longe das bases que constituem nossa sociedade. Além disso, seus impactos são desiguais, entre outras dimensões, em termos de classe, raça, gênero e etnia. O que se estabeleceu desde o início desse período foi a marca da instabilidade e da incerteza. Ainda mais em nosso país. Para o mundo do trabalho, como de resto para outras dimensões da vida, estando 


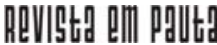

\} CLASSE TRABALHADORA, PRECARIZAÇÃO - SANTANA, M. A. \}

DOI: $10.12957 /$ REP.2021.60293

ainda em meio ao processo, é também difícil cravar em pontos exatos como este se desenvolverá. Porém, estão apontadas algumas tendências para seus desdobramentos futuros, a partir de linhas muito gerais, sendo muitas delas continuidades das já presentes desde antes da pandemia.

O quadro no futuro próximo em nosso país vai caminhando para o que seria uma combinação devastadora sanitária e socialmente. No plano sanitário, o número estratosférico de mortes que aumenta e impacta tragicamente a sociedade, o negacionismo presidencial e sua opção pela economia em detrimento da vida que travam qualquer possibilidade de ação - digna de ser chamada por esse nome - contra a pandemia, bem como um processo de vacinação claudicante, indicam que a situação ainda perdurará sem horizontes de saída visíveis à frente]. No plano social, o fim do chamado Auxílio Emergencial — ou a sua possível substituição, mas ainda incerta, por outra política mais "recortada" — terá impacto negativo fortíssimo em termos de pobreza. Segundo dados da FGV Social ${ }^{16}$, estaríamos falando de algo em torno de 15 milhões de pessoas voltando àquele patamar.

Por ora, o que se tem é um Auxílio com prazo determinado quatro parcelas a partir de abril de 2021 - e com valor ainda mais diminuto ${ }^{17}$, o qual não terá os mesmos impactos do fornecido anteriormente. Isso se associará ao aumento ainda maior do desemprego, já que, com a chamada abertura, mais e mais pessoas voltarão a procurar emprego. Segundo Felipe Salto $^{18}$, diretor executivo da Instituição Fiscal Independente (IFI) do Senado Federal, para 2021, "o mercado de trabalho segue muito precário e a ocupação deve cair perto de $9 \%$, neste ano, para recuperar apenas pouco menos de $2 \%$ no ano que vem. Um contingente importante de pessoas precisará de algum auxílio". As perspectivas em termos sociais assumem tons explosivos, ainda mais quando associadas àquelas do mundo do trabalho.

No plano laboral, os sinais indicam fortemente a direção de um aumento da precarização para a classe trabalhadora. O modo de organização da vida e do trabalho pelo chamado processo de uberização (SLEE, 2018; SANTANA; BRAGA, 2020; ANTUNES, 2020), que vai avançando nos mais diversos setores de produção e reprodução, aponta para isso. Em termos de formato plataformizado, o momento atual do capitalismo se encaminha para a articulação entre um espalhamento ainda maior da informalidade, da manutenção de índices altos de desemprego e do aumento da flexibilização, mesmo dos setores formalizados, crescentemente pre-

\footnotetext{
${ }^{16}$ Disponível em: https://economia.estadao.com.br/noticias/geral,fim-da-concessao-de-auxilios-deve-devolver-15milhoes-a-pobreza-no-proximo-ano,70003469132. Acesso em: 12 out. 2020.

17 "O valor do benefício varia de acordo com a composição da família: - Se a família for composta por apenas uma pessoa, o benefício é de R\$150,00 por mês; - Se a família for composta por mais de uma pessoa, o benefício é de R\$ 250,00 por mês; - Se a família for chefiada por mulher sem cônjuge ou companheiro, com pelo menos uma pessoa menor de dezoito anos de idade receberá, mensalmente, $\mathrm{R} \$ 375,00^{\prime \prime}$, conforme https://www.caixa.gov.br/auxilio/ auxilio2021/Paginas/default.aspx. Acesso em: 14 abr 2021.

${ }^{18}$ Disponível em: https://economia.estadao.com.br/noticias/geral,governo-busca-saida-legal-se-tiver-de-prorrogarpagamento-do-auxilio,70003525632. Acesso em: 24 nov. 2020.
} 


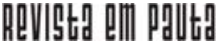

\} CLASSE TRABALHADORA, PRECARIZAÇÃO - SANTANA, M. A. \}

DOI: $10.12957 /$ REP.2021.60293

carizados. A maior ou menor intermitência de ciclos/acessos de trabalho e de não trabalho, bem como sua transversalidade pelos diversos setores da classe trabalhadora, vem aparecendo como tônica em diferentes momentos. Nestes termos, o aumento da precarização do trabalho e seus impactos na vida de trabalhadores e trabalhadoras darão as tintas na composição do cenário a vir.

Este quadro vem colocando e colocará cada vez mais questionamentos e exigências ao conjunto da classe trabalhadora em termos de orientação, organização e mobilização. Há um claro desafio histórico aí presente. Cremos que alguns aspectos do movimento dos/as entregadores/ as podem nos servir com algumas indicações importantes. Se comparados a um movimento da classe trabalhadora do período anterior, poderia parecer impossível que trabalhadores/as submetidos/as a tal informalidade e precarização da vida e do trabalho pudessem conseguir sequer tempo de pensar em se organizar e de articular reivindicações. Além disso, a aceleração dos fluxos da vida pelo neoliberalismo já vinha mesmo afetando bastante as possibilidades de encontro, práticas coletivas, tendo impactos políticos claros, sem falar da pervasividade da ideologia do empreendedorismo. No entanto, deve-se pensar que, em outros momentos históricos, a classe trabalhadora, também desprotegida e atuando em situação bastante adversa, conseguiu desenvolver formas de organização e luta correspondentes aos contextos nos quais atuava. Além disso, a juventude trabalhadora precária tem estado presente atualmente em movimentos importantes pelo mundo todo, utilizando variados formatos para a canalização da conflitividade social (BRAGA; SANTANA, 2020).

Uma questão que será interessante avaliar em termos de passos futuros se relaciona com as formas organizativas às quais a classe trabalhadora lançará mão. Os movimentos que vêm ocorrendo, muitas vezes distantes e à revelia das estruturas sindicais convencionais, podem seguir com as mesmas características apresentadas até aqui. Por outro lado, também podem se aproximar, buscando interlocução com formas tradicionais de organização e produzindo entre eles uma tensão criativa entre inovação tática e persistência (MCADAM; TARROW; TILLY, 2009).

Já existem diversas associações e sindicatos representando a classe trabalhadora, muito moldados em termos de um mundo do trabalho que hoje já está bem modificado e no qual têm e terão de lidar e se mover. Eles, em seus setores progressistas, têm uma longa e importante trajetória de conquista e garantia de direitos para a classe trabalhadora. Não há por que, e nem como, prescindir deles. Há perdas e ganhos nessas escolhas na direção de mudanças de cultura e estrutura. Precisamos escapar às visões polarizadas e limitantes, que veem oposição excludente entre sindicatos e outros formatos de organização que vêm surgindo no mundo do trabalho. Mais rico e produtivo seria pensar nas possíveis sinergias e potências das relações entre eles. Em termos de mobilização, teremos de ver como eles 


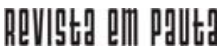

\} CLASSE TRABALHADORA, PRECARIZAÇÃO - SANTANA, M. A. \}

DOI: $10.12957 /$ REP.2021.60293

buscarão incorporar sempre mais trabalhadores/as nas mobilizações da classe trabalhadora, bem como de que modo outros setores e categorias podem somar nessa luta contra a precarização do trabalho e da vida.

Há, entre outras, algumas frentes importantes possíveis que podem vir a se associar com essa pauta. Uma delas, fundamental para um conjunto enorme de trabalhadores e trabalhadoras às voltas com a gestão de sua vida e de seu trabalho nas plataformas digitais, ainda que haja uma diversidade de opiniões sobre isso no interior desses setores da classe trabalhadora, é que a regulação se estabeleça. Dessa maneira, como tem acontecido em outros países, ainda que com dificuldade, as empresas serão obrigadas a reconhecer os vínculos de emprego que mantêm com seus/as trabalhadores/as e se responsabilizar por eles/as. Outra possibilidade é o desenvolvimento de mecanismos digitais coletivos, próprios dos/as trabalhadores/as, para a gestão de seu trabalho. Mais difícil, mas também importante e necessária como ponto de disputa, é a discussão dos próprios algoritmos utilizados pelas empresas e seu funcionamento. Eles não são neutros, e reside ali o centro do processamento de subordinação e exploração dos novos tempos capitalistas.

Há tendências importantes aflorando desses movimentos em curso no mundo do trabalho. Nem todas são necessariamente novas nos repertórios de ação, mas podem auxiliar na construção de caminhos para a luta da classe trabalhadora no país. As condições materiais vão tornando cada vez mais factível e necessária a ideia do chamado sindicalismo tipo movimento social (MOODY, 2001) de articulações entre o movimento sindical e os movimentos sociais. Neste sentido, também assumem cada vez mais importância a articulação desses movimentos em coalizões com diferentes formatos, estruturas, dimensões e dinâmicas, que podem ampliar escalas, intensidades e potências das ações coletivas.

A combinação entre formas de organização horizontais e outras mais verticais; entre ações espontâneas e outras mais vertebradas, com forte assento no trabalho de base e em formas democráticas de debate e deliberação, e atualmente indispensáveis entre ação no mundo real e ação no mundo digital; o intenso uso dos aplicativos de mensagem e das redes sociais, tanto no sentido organizativo quanto no de agitação e propaganda etc.: tudo isso tem fornecido características interessantes, hoje, e que apontam ser a possível perspectiva futura. 


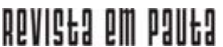

\} CLASSE TRABALHADORA, PRECARIZAÇÃO - SANTANA, M. A. \}

DOI: $10.12957 /$ REP.2021.60293

\section{Referências}

ABÍLIO, L. Plataformas digitais e uberização: globalização de um sul administrado? 2020. Disponível em: https://periodicos.uff.br/contracampo/article/ view/38579/html_pt. Acesso: 1 out. 2020.

ABÍLIO, L. et al. Condições de trabalho de entregadores via plataforma digital durante a Covid-19. Revista Jurídica Trabalho e Desenvolvimento Humano, Campinas, Procuradoria Regional do Trabalho da 15ª Região, 2020.

ANTUNES, R. (Org.). Uberização, trabalho digital e indústria 4.0. São Paulo: Boitempo, 2020.

ANTUNES, R.; FILGUEIRAS, V. Plataformas digitais, uberização do trabalho e regulação no capitalismo contemporâneo. Revista Contracampo, Niterói, v. 39, n. 1, 2020.

ANTUNES, R.; SANTANA, M. A. Dinâmicas da ação coletiva no Brasil contemporâneo: encontros e desencontros entre o sindicalismo e a juventude trabalhadora. Cad. CRH, Salvador, v. 28, n. 75, 2015.

BRAGA, R. A política do precariado - Do populismo à hegemonia lulista. São Paulo: Boitempo, 2012.

CAMPOS, A. Sindicalismo no contexto de pandemia. 2020. Disponível em: https://www.cesit.net.br/wp-content/uploads/2020/06/Sindicalismo-nocontexto-de-pandemia-no-Brasil_andersoncampos.pdf. Acesso em: 8 out. 2020.

CORSEUIL, C.H. e FRANCA, M. Inserção dos jovens no mercado de trabalho em tempos de crise. Boletim Mercado de Trabalho - Conjuntura e Análise, IPEA, $\mathrm{n}^{\circ}$ 70, 2021.

DIEESE. Boletim Emprego em Pauta, N. 18, 2021 a.

DIEESE. Balanço das Greves de 2020, Estudos \& Pesquisas, N. 99, 2021 b.

DUTRA, R.; FESTI, R. A greve dos entregadores. 2020. Disponível em: https:/ /jornalggn.com.br/artigos/a-greve-dos-entregadores-por-renata-dutra-ericardo-festi/. Acesso em: 30 jul. 2020.

DRUCK, G. Os sindicatos, os movimentos sociais e o governo Lula: cooptação e resistência. Observatório Social de America Latina, ano VI, N. 19, Buenos Aires, CLACSO, p. 329-340, 2006.

FRASER, N.; HONNETH, A. Redistribution or recognition? A political-philosophical exchange. New York: Verso Books, 2003.

GALVÃO, A. A greve, o breque, o trampo: a luta dos entregadores é a luta dos trabalhadores. 2020a. Disponível em: http://www.esquerdadiario.com. br/A-greve-o-breque-o-trampo-a-luta-do-entregadores-e-a-luta-dos-trabalha dores. Acesso em: 5 jul. 2020. 


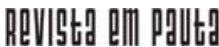

\} CLASSE TRABALHADORA, PRECARIZAÇÃO - SANTANA, M. A. \}

DOI: 10.12957/REP.2021.60293

GALVÃO, A. O movimento dos entregadores. 2020b. Disponível em: https:/ /aterraeredonda.com.br/o-movimento-dos-entregadores/https://aterrae redonda.com.br/o-movimento-dos-entregadores/. Acesso em: 5 ago. 2020.

LADOSKY, M. H.; RODRIGUES, I.. A CUT e o sindicalismo brasileiro nos anos recentes: limites e possibilidades. Tempo Social, v. 30, p. 53-76, 2018.

LI, S.L., PEREIRA, R.H.M., PRETE Jr, C.A., et al. Higher risk of death from COVID-19 in low-income and non-White populations of São Paulo, Brazil. BMJ Global Health 2021

MCADAM, D.; TARROW, S.; TILLY, C. Para mapear o confronto político. Lua Nova: Revista de Cultura e Política, n. 76, 2009.

MAZZA, L.; AMOROZO, M.; BUONO, R. Pandemia do desemprego. 2020. Disponível em: https://piaui.folha.uol.com.br/pandemia-do-desemprego/ https://piaui.folha.uol.com.br/pandemia-do-desemprego/. Acesso em: 10 nov. 2020.

MOODY, K. Workers in a lean world; union in the international economy. London: Verso, 2001.

NERI, M. C. Juventudes, Educação e Trabalho: Impactos da Pandemia nos Nem-Nem. Rio de Janeiro: FGV Social, 2021.

OLIVEIRA, D. A.; POCHMANN, Marcio (Orgs.). A Devastação do trabalho: a classe do labor na crise da pandemia. Brasília: Gráfica e Editora Positiva: CNTE - Confederação Nacional dos Trabalhadores em Educação e Grupo de Estudos sobre Política Educacional e Trabalho Docente, 2020.

OLIVEIRA, R. V.; BRIDI, M. A.; FERRAZ, M. (Org.). O sindicalismo na Era Lula: paradoxos, perspectivas e olhares. Belo Horizonte: Fino Traço Editora, 2014.

PRAUN, L. Breque dos Apps: a ocupação das ruas reinventa o sentido de coletividade. 2020. Disponível em: https://www.esquerdadiario.com.br/ Breque-dos-Apps-a-ocupacao-das-ruas-reinventa-o-sentido-de-coletivi dade. Acesso em: 20 jul. 2020.

SANTANA, M.; BRAGA, R. \#BrequeDosApps: enfrentando o uberismo. 2020. Disponível em: https://blogdaboitempo.com.br/2020/07/25/bre quedosapps-enfrentando-o-uberismo/. Acesso em: 25 jul. 2020.

SANTANA, M; ANTUNES, R.; FRAGA, A. Forças sociais do trabalho e a nova desertificação neoliberal no Brasil. In: Trabalho, regressão de direitos e serviço social. Rio de Janeiro: Mórula Editorial, 2020.

SILVA, E. R. A da; VAZ, F.M. Os jovens que não trabalham e não estudam no contexto da pandemia da COVID-19 no Brasil. Boletim Mercado de Trabalho - Conjuntura e Análise, IPEA, nº 70, 2021. 


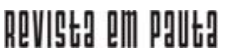

\} CLASSE TRABALHADORA, PRECARIZAÇÃO - SANTANA, M. A. \}

DOI: $10.12957 /$ REP.2021.60293

SINGER, A. Quatro notas sobre as classes sociais nos dez anos do lulismo. In: FUNDAÇÃ̃O PERSEU; FUNDAÇÃO FRIEDRICH EBERT (Org.). Classes? Que classes? São Paulo: Fundação Perseu Abramo; Fundação Friedrich Ebert, 2014.

SLEE, T. Uberização. A nova onda do trabalho precarizado. São Paulo: Elefante, 2018.

DOI: $10.12957 /$ rep.2021.60293

Recebido em 30 de novembro de 2020.

Atualizado em 28 de maio de 2021.

Aprovado para publicação em 18 de dezembro de 2020.

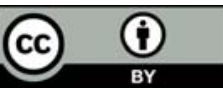

A Revista Em Pauta: Teoria Social e Realidade Contemporânea está licenciada com uma Licença Creative Commons Atribuição 4.0 Internacional. 